\title{
Sex-specific responses to simulated territorial intrusions in the common cuckoo: a dual function of female acoustic signaling
}

\author{
Csaba Moskát ${ }^{1,2}$ (D) Márk E. Hauber ${ }^{3}$
}

Received: 12 December 2018 / Revised: 18 March 2019 / Accepted: 25 March 2019 /Published online: 22 April 2019

(C) The Author(s) 2019

\begin{abstract}
The two-note call of the male common cuckoo (Cuculus canorus), the so-called "cu-coo", is well known to people as a natural and cultural signal. However, the so-called "bubbling" call of the female cuckoo is almost unknown to most, and its function in the social organization of cuckoos remains understudied. We carried out a study of a possible intraspecific communication function of female bubbling calls, using playbacks to female cuckoos in their natural environment. Regarding vocal responses, both female and male cuckoos paid attention to the bubbling calls as they consistently responded acoustically by calling but did not so during control playbacks of collared dove (Streptopelia decaocto) calls. Accordingly, in about $63 \%$ of trials, females approached the loudspeaker closely and $81 \%$ uttered bubbling calls themselves during the experiment. These results are consistent with a function that the bubbling call plays a role in territorial signaling and defense among females. Male cuckoos also showed strong responses to playbacks of bubbling calls, as they approached the speaker and themselves called in $94 \%$ of playbacks; this is consistent with a scenario that they are interested in unfamiliar, new females in the area. Specifically, males approached the speaker repeatedly by flight, often flew around it and then perched on a tree, and uttered different call types beside the general "cu-coo" (e.g., quick "cu-cu-coo", "gowk" call, and "guo" call). Our results represent an illustrative example that a simple female call may have multiple functions, as the cuckoo bubbling call advertises territory need for female cuckoos and attracts males.
\end{abstract}

\section{Significance statement}

Avian brood parasites lay their eggs in nests of other bird species, causing hosts to incubate, feed, and rear the parasitic offspring. Parasitic adult common cuckoos maintain a complex acoustic communication system, but female cuckoo calls are only beginning to be studied. The basic intraspecific functions of females' sparrowhawk-like "bubbling calls" have not yet been characterized, whereas interspecifically, they use it for reducing antiparasitic attacks by their hosts. Our playback experiments with bubbling calls revealed that both female and male cuckoos responded acoustically to unfamiliar bubbling calls and more males than females approached the speaker, relative to control playbacks. We conclude that bubbling call has dual basic intraspecific functions: mate attraction, and territorial spacing.

Keywords Acoustic playback $\cdot$ Brood parasitism $\cdot$ Common cuckoo $\cdot$ Female-female communication $\cdot$ Male attraction $\cdot$ Territory

Communicated by M. Soler

Csaba Moskát

moskat@nhmus.hu

1 MTA-ELTE-MTM Ecology Research Group, A Joint Research Group of the Hungarian Academy of Sciences, the Biological Institute of the Eötvös Loránd University and the Hungarian Natural History Museum, MTM, Baross u. 13., Budapest H-1088, Hungary

2 Zoological Department, Hungarian Natural History Museum, Baross u. 13., Budapest H-1088, Hungary

3 Department of Evolution, Ecology and Behavior, School of Integrative Biology, University of Illinois at Urbana-Champaign, 505 S. Goodwin Avenue, Urbana-Champaign, IL 61801, USA

\section{Introduction}

Acoustic communication plays a role in the social communication systems of many arthropod and vertebrate species (Bradbury and Vehrencamp 1998; Ladich and Winkler 2017), including birds, as well as in male-male, female-female, and intersexual relationships (Catchpole and Slater 2008). Oscine birds have evolved the most complex vocal repertoires (MacDougall-Shackleton 1997; Beecher and Brenowitz 2005), and their singing interactions are striking examples of acoustic communication of territoriality and mate attraction in their communication networks (Naguib 2005). However, acoustic communication is also important in suboscine and 
non-passerine birds (e.g., Appleby et al. 1999; Rek 2014; Wojas et al. 2018). The simpler call structure in these lineages is nonetheless still often used in territorial occupancy and other social and reproductive interactions (Budka and Osiejuk 2013, 2017; Moskát et al. 2017a).

Long-ranging calls are often used to advertise the presence of a territorial owner for multiple conspecific receivers (McGregor and Dabelsteen 1996). Males in most species, and females of many bird species, vocalize to advertise and defend their own territories (e.g., Fedy and Stutchbury 2005). In obligate brood parasitic birds, such roles of territory defense may have less importance as females lay their eggs in the nests of other species. However, female brood parasites may also defend their nest-searching and egg-laying areas from conspecifics so as to monopolize access to this critical resource for breeding (Hauber and Dearborn 2003). For example, females of shiny cowbirds (Molothrus bonariensis) and screaming cowbirds (Molothrus rufoaxillaris) show no territoriality (Scardamaglia and Reboreda 2014). However, females of the brown-headed cowbird (Molothrus ater) and the common cuckoo (Cuculus canorus) may locate, guard, and protect their host nests from conspecifics and may have separate egg-laying territories (Gärtner 1981; Wyllie 1981; Dröscher 1988; Hauber et al. 2001; Honza et al. 2002; Davies 2015; but see Vogl et al. 2004).

The brood parasitic common cuckoo is famous for its twopart "cu-coo" calls (Chance 1940). This call's structure seems to be similar in the Palearctic (Payne 1986; Lei et al. 2005; Payne 2005; Wei et al. 2015), although it shows individual variability (Jung et al. 2014; Li et al. 2017; Zsebök et al. 2017). This general, so-called advertising call (Lei et al. 2005) is uttered by the male during the breeding season, and it primarily serves as signal of territorial defense and aggression (Moskát et al. 2017a; Tryjanowski et al. 2018). Females are known for their chuckle bubbling, typically called the "bubbling call" ("bubble call or hinny" in Chance 1940; Wyllie 1981; Davies 2000, 2015; Lei et al. 2005), or "chuckle call" (Witherby et al. 1940; York and Davies 2017). This call is short (ca. 2-3 s), with the frequency between 1000 and $2000 \mathrm{MHz}$ (Fig. 1). However, this bubbling call is uttered far less often than the male "cu-coo" call, and it is more difficult to recognize, even for ornithologists. It is somewhat similar to the lesser woodpeckers' (Dryobates minor) "pee-peepee...," or certain strophes of many birds' songs (e.g., nightingale Luscinia megarhynchos). Chance (1940) thought it is

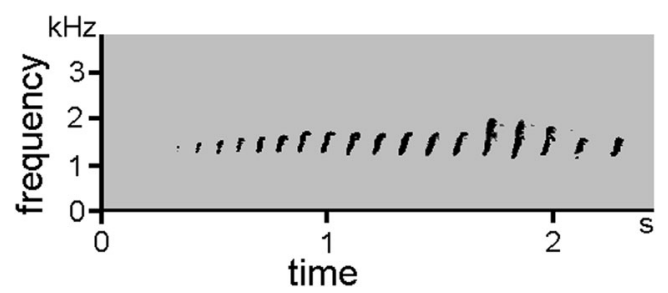

Fig. 1 The spectrogram of a female cuckoo's bubbling call similar to the call of the green woodpecker (Picus viridis), Mikulica et al. (2017) mentioned similarity with little grebe (Tachybaptus ruficollis), and it seems also be acoustically similar to goshawk (Accipiter gentilis) or sparrowhawk (A. nisus) calls (York and Davies 2017).

The function of female calls remains poorly understood. Intraspecifically, they may play a role in male-female communication (Lei et al. 2005) and the recognition of conspecifics (Kim et al. 2017). It may probably play a role in maintaining a territorial system in cuckoos, as previous radio telemetry studies revealed that both female and male cuckoos are territorial (Nakamura and Miyazawa 1997; Honza et al. 2002). Female cuckoos may defend their egg-laying areas as exclusive territories and their bubbling calls may serve as "keep out" signals to other females (Davies 2015). Interspecifically, a recent study showed similar effects on songbirds by the sparrowhawk call and by the female cuckoo's bubbling call on two passerines (the reed warbler Acrocephalus scirpaceus and the great tit Parus major) in different situations (at nest or feeder of tits). This effect on passerines may aid laying females to avoid attack by the host, fooling the hosts that the laying female is a hawk (York and Davies 2017). Accordingly, great reed warblers did not utter any alarm calls to bubbling calls when these were played alone to these hosts at their nests (CM unpubl. data), and, thus, bubbling calls are unlikely to function in nest searching by the female cuckoos. However, it is plausible that the female parasite's call may play an important role in other, either intra- or interspecific social communication of cuckoos.

We studied the function of the female cuckoo's bubbling calls in male-female and female-female cuckoo communication with a playback experiment in Central Hungary. At our site, the host species is the great reed warbler (Acrocephalus arundinaceus) (Moskát et al. 2006), a high-quality host for this brood parasite (Kleven et al. 1999; Leisler and SchulzeHagen 2011). We assessed the following non-mutually exclusive hypotheses: (i) The bubbling calls of female cuckoos are used in female signaling, which may help them to recognize each other as a part of territorial behavior within their host's breeding area. We predict strong female responses to the playback of female calls over heterospecific control calls. (ii) The female bubbling call is a signal for males in male-female communication. We predict strong responses to female calls by by males during the playback experiment over controls.

\section{Methods}

\section{Study area}

The study was conducted in an $\sim 25-\mathrm{km}$ radius circle around Apaj ( $47^{\circ} 6^{\prime} 53.9^{\prime \prime} \mathrm{N}$; $\left.19^{\circ} 5^{\prime} 21.2^{\prime \prime} \mathrm{E}\right)$, central Hungary, about $50 \mathrm{~km}$ south of Budapest. In this area, cuckoos occur in the reed 
beds of small irrigation channels, complemented with trees and bushes on the banks; here, cuckoos parasitize only great reed warblers, at a high frequency (ca. 50\%; Zölei et al. 2015). The study was conducted in 2018, between April 28 and May 12, in the early part of the breeding season of cuckoos and great reed warblers, as the frequency of male and female cuckoo calls is decreasing with the progress of the breeding season (Wyllie 1981; Deng et al. 2019). Playbacks were started in the mornings (5:30-10 h CET) or in late afternoons (18-19 h CET) on windless days. It was not possible to record the data blind to treatment because the experimenter could hear the identity of the playback stimulus type.

\section{Playback experiments}

Female cuckoo calls were played at points on the banks of channels where a female cuckoo's bubbling call could be just heard from about $30-40 \mathrm{~m}(<50 \mathrm{~m})$. The playback equipment was set up using bushes as hides in about $2 \mathrm{~min}$, and the experiment was started immediately after this, so that female cuckoos did not have much time to leave the study site until the playback started. This strategy was successful as flying or calling females indicated their presence in the vicinity during and immediately following the playback. A loudspeaker JBL Xtreme $(40 \mathrm{~W})$ was set on trees at about $1.5 \mathrm{~m}$ high and connected with a 20-m cable to a Lenovo TAB 2 A7 tablet containing playback files in wav 16-bit format. Each playback file was prepared to match ca. $90 \mathrm{~dB}$, measured by the Voltcraft SL-100 sound level meter at about $1 \mathrm{~m}$ from the speaker (Conrad GmbH, Kalchreuth, Germany), and each was played only once (i.e., to one focal bird, only). Cuckoos were monitored while the observer hid in the bushes. Observations of cuckoo movements, together with cuckoo calls emitted during playback, were continuously recorded by a Marantz PMD-620 MKII recorder equipped with a Sennheiser ME66 shotgun microphone, a FEL MX mono preamp, a Rode PG2 pistol grip, a Rode WS6 Deluxe windshield, and an AKG K141 MKII semi-open monitoring headphone.

For playbacks, a 2-min sound file was used, containing a ca. 2-s bubbling call three times per $30 \mathrm{~s}$, and these units were repeated two times with a 15 -s silent period, similar to the file structure already used for playback to male cuckoos (Moskát et al. 2017a). Prolonged cuckoo vocal responses were also monitored for 2 min after playback had terminated. Bubbling calls were collected between 2015 and 2018 with care not to record in the same territory twice, and each call was used for playback only once. Previous VHS and GPS telemetry of cuckoos in our study area (Moskát et al. 2017a, 2019) revealed that male and female cuckoos maintain small, ca. 1$\mathrm{km}$-long territories along the channels, although their territories may overlap each other, at least partly. Their site fidelity during the breeding season was confirmed by a GPS telemetry study from previous years (Bán et al. 2018). Sometimes, we observed several female cuckoos staying closely to each other along the channels, where good-quality reed was available for their great reed warbler host. In order to avoid pseudoreplication of observations caused by testing of the same individual bird twice (c.f. Kroodsma 1989), we chose a female at least $1 \mathrm{~km}$ apart from the previous playback experiment (Moskát et al. 2017a). Typically, additional female cuckoos also occurred within this distance. For example, we counted five female cuckoos along $1.76 \mathrm{~km}$ in a section of channel, and eight females along another, 4.13-km section.

During the 2-min observation of cuckoos during playbacks and the 2-min post-playback period, we observed the behavior of both female and male cuckoos. Males are monomorphic (gray), and females are dimorphic (gray or rufous). In our study area, the frequency of the rufous form is high $(60 \%)(n=30$; Honza et al. 2006). Only the strictly rufous (hepatic) form can be easily identified in the field. Although gray females and males also have some unique characteristics in their plumage (Mann 2014), their identification at a distance typically relies on call recognition to avoid uncertainty in the field. For this reason, we identified females by their sex-specific bubbling calls and separated them from males typically vocally, as males frequently utter their specific "cu-coo" call or their other calls.

Altogether, 16 playback trials with bubbling calls were conducted. All observations refer to cuckoos within a 50-m "action" radius estimated around the loudspeaker during the 2-min playback and 2-min post-playback periods. (For this reason, cuckoos staying consistently further than $50 \mathrm{~m}$ during the 2-min playback and 2-min post-playback periods were treated as non-responders.) The following variables were measured:

For females:

(i). Number of females heard or seen.

(ii). Starting distance (m). Distance between the focal female and the loudspeaker when the experiment started.

(iii). Closest distance (m). It was estimated if the female approached the loudspeaker by flight or perched on a tree. If the female did not move, it is equal to the starting distance.

(iv). Largest distance (m). The largest distance between the focal female and the loudspeaker. It is equal to the starting distance if the cuckoo did not move.

All distances in (ii)-(iv) were estimated after training with a Bushnell rangefinder (model: Yardage Pro 800).

(v). Number of calls by the female(s). The experiment was started 2 min after hearing the bubbling call of a nearby female cuckoo. Number of calls means the number of bubbling calls heard during the 2-min playback and 2min post-playback periods.

For males:

The same variables were used as for females, with some modification: The focal male was the closest male when the 
experiment started, but typically, more than one male approached the loudspeaker. For this reason, the shortest and longest distances are related to the closest and farthest approach by any male, not strictly the focal male. The last variable for the females was replaced by the number of male call types. As male cuckoos generally call often, the so-called advertising call ("cu-coo"; Lei et al. 2005) was uttered by all males during the observation periods. We also counted other types of calls heard during the trials and the post-playback period.

We categorized calls of male cuckoos following Lei et al. (2005):

(a) "cu-coo": general advertising call.

(b) "gowk": a gruff, snoring call, frequently repeated by 2-4 times, uttered by males in many situations for communication with other male or female cuckoos, even during flying. It is called "wah" by Chance (1940).

(c) "guo": a harsh call (Lei et al. 2005), somewhat similar to the "gowk" call. Wyllie (1981) thinks that it is a variant of the former call.

(d) We also used the male call type quick "cu-cu-coo" sequence, as described by Lei et al. (2005). The male's quick calling sequence, the three-note "cu-cu-coo", often repeated 2, 3, or even more times, is heard in the vicinity of females (Cramp 1985; Lei et al. 2005; Payne 2005; Erritzøe et al. 2012). It was termed as "the often heard excited chuckle of the male" by Chance (1940), which cannot be confused with the bubble of the female (Chance 1940).

For controls in our experiments, we played 2 min of collared dove (Streptopelia decaocto) calls, with a file structure similar to that used for the bubbling calls (see also Moskát et al. 2017a). Most of the 16 control files were recorded in 2016 (two files in 2018). We conducted 16 control playback sessions and observed cuckoo behavior in the same way as we did in the bubbling call experiment $(2+2$ min during playback and in the post-playback period). The same response metrics were recorded for both females and males as for the bubbling call playbacks (see above).

\section{Statistical analysis}

Cuckoo response behaviors were analyzed by principal component analysis (PCA), using the SPSS ver. 17 programs package (SPSS Inc., Chicago, IL, USA). Females and males were analyzed separately. Each PCA was started from the correlation matrix, and the number of components was determined by eigenvalues greater than 1.0 , while also taking into account the cumulative variance explained. No rotation was applied on component loadings.

We used generalized linear models to test how our treatment affected the cuckoos' responses. In the first model, the dependent variable was the movement distance, which was tested with treatment (experiment/control) and sex as predictor factors, and with starting distance as a covariate, and the interaction of these terms. In the second model, the dependent variable was the number of calls, which was tested with the same factors as in the first model, and also included their interaction terms.

We used mostly parametric tests, but applied nonparametric tests for data where sample sizes were low and/or not normally distributed. All analyses were done by SPSS ver. 17 program package (SPSS Inc., Chicago, IL, USA).

\section{Data availability}

We placed some typical bubbling calls of female common cuckoos into the bioacoustics archive Xeno-Canto (https:// www.xeno-canto.org) with the following codes: XC422394, XC422426, and XC422443. The datasets analyzed for this report are available from the corresponding author upon requests for reasonable use.

\section{Results}

Playbacks of female cuckoo calls attracted more males than females at a site (females: median $=1$, range $=1-2$; males: median $=2$, range $=0-3$; Wilcoxon signed paired test: $n=$ $16, z=-3.0, P=0.003$; Fig. 2). As our experiments started at trial sites where a female cuckoo was observed to utter the bubbling call (see the "Methods" section), the cumulative numbers of females in bubbling and dove control trials represent these cases. (In other words, at least one female at each trial was present already and not initially attracted by the playback.) The number of female cuckoos counted was almost the

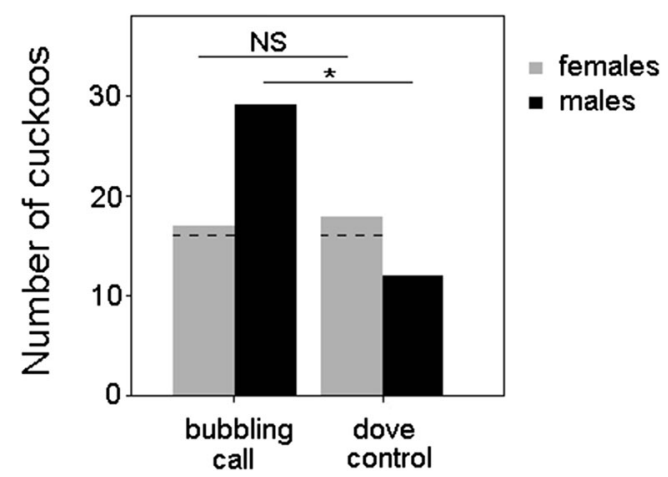

Fig. 2 Number of female and male common cuckoos detected within $50 \mathrm{~m}$ around the speaker in bubbling call $(n=16)$ and collared dove control playbacks $(n=16)$. NS: not significant $(P=0.550)$; $* P=0.001$. Please be aware that each experimental trial was started at a site where a female cuckoo was present, i.e., heard just before the trial, so the number of female cuckoos in both categories represents the number of cuckoos occurring naturally at a trial site. For this reason, the minimal number of females that were already staying at trial sites is shown by dashed lines 
same in the two types of playbacks (17 females in bubbling call and 18 females in dove control), showing that bubbling calls did not attract more female cuckoos from nearby territories (Fig. 2; Mann-Whitney $U$ test: $U_{16,16}=120.0, P=$ $0.551)$. However, the number of males detected during control playback was less than half ( 12 males) than counted during the bubbling call playbacks (29 males; Fig. 2; Mann-Whitney $U$ test: $U_{16,16}=47.0, P=0.001$ ), showing an attractive effect of bubbling calls for adjacent males.

Ten females out of 16 trials $(62.5 \%)$ flew closer to the loudspeaker and approached it closely (mean $=13.3 \mathrm{~m}$, $\mathrm{SD}=6.481$, range $3-25 \mathrm{~m}$ ). All focal males $(100 \%)$ approached the speaker except one, which was always outside the $50-\mathrm{m}$ action radius (ca. $60-70 \mathrm{~m}$ ) from the speaker (mean $=6.4 \mathrm{~m}, \mathrm{SD}=5.110$, range 2-15 m). Males approached closer to the speaker than females, both for all cuckoos (Levene test $F=0.10, P=0.921 ; t$ test $t_{16,16}=2.233, d f=30$, $P=0.033$; Fig. 3a), and for the subset of only those individuals that approached the speaker (Levene test $F=0.464, P=$ 0.502 ; $t$ test $t_{15,10}=2.972, d f=23, P=0.007$; Fig. $3 b$ ). Contrary to playback experiments with bubbling calls, neither female nor male cuckoos approached the loudspeaker during the control playbacks with dove calls (females: Levene test $F=3.743, P=0.063 ; t$ test $t_{16,16}=-4.873, d f=30, P<0.001$; males: Levene test $F=3.751, P=0.062 ; t$ test $t_{16,16}=-5.231$, $d f=30, P<0.001$; Fig. 3a).

Thirteen females ( $81.25 \%$ of the 16 trials) uttered bubbling call during the 2-min playback period (median $=1$, range $=0$ 5 calls per site, $n=16$ ) and eight of these birds also called in the 2 -min post-playback period $(50 \%$; median $=0.5$, range $=$ $0-3$ calls per trial site, $n=16$; Fig. 4; Wilcoxon test: $z=-$ 1.933, $P=0.053)$. The difference between the playback and post-playback periods was significant when tested for number of bubbling calls uttered by the focal females (Wilcoxon

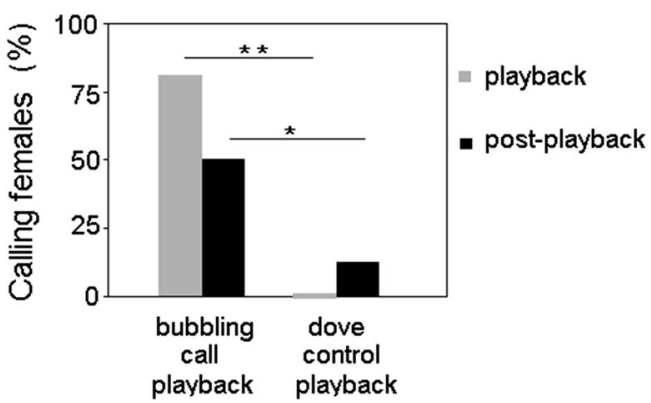

Fig. 4 Number of calling females during the 2-min playback and the 2min post-playback period, when either female cuckoo bubbling calls $(n=$ 16 ) or dove calls (control; $n=16$ ) were played. $* P<0.05$, $* * P<0.001$

signed test, $n=16, z=-2.486, P=0.013)$. No bubbling call was heard during the 2-min playback periods of the dove controls, and only two such calls were detected in the postplayback period of controls. For this reason, bubbling calls differed significantly from the controls in the 2-min playback period (Mann-Whitney $U$ test, $U_{16,16}=32.0, P<0.001$ ). A significant difference was also found between responses to bubbling playbacks and control playbacks in the postplayback period (Mann-Whitney $U$ test, $U_{16,16}=79.0, P=$ 0.022).

At almost every playback, the male cuckoos' two-note call, the "cu-coo," could be heard. Other male call types were also heard, but at a lower percentage of trials (Table 1). The "gowk" call of males seems to be the most characteristic call in response to bubbling call playbacks when compared with dove call control playbacks (Fisher exact test, $P=0.001$ ). The presence of other male call types at a site (Table 1) did not differ between bubbling and control playbacks (Fisher exact test, "cu-coo" $P=0.188$, quick "cu-cu-coo" 0.914 , and "guo" $P=0.487)$.

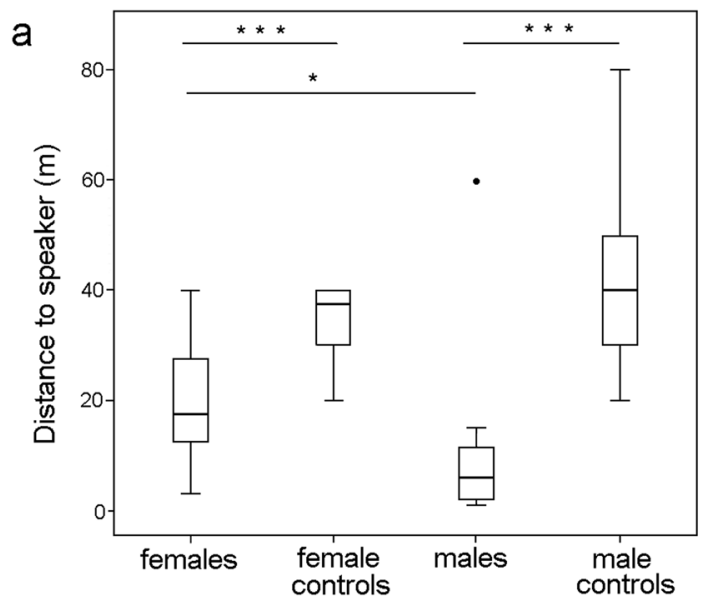

b

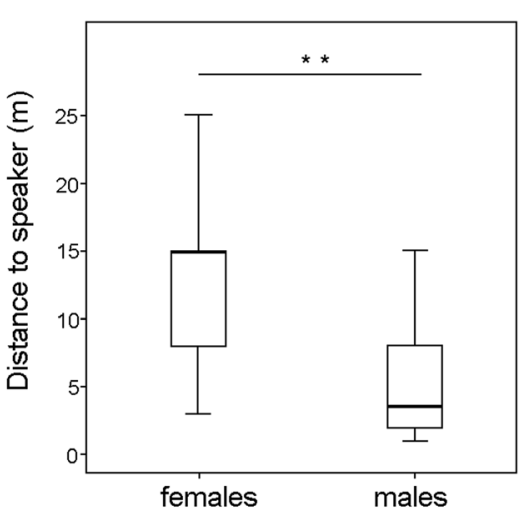

Fig. 3 Box plots of closest distances of female and male common cuckoos approaching the loudspeaker in playback trials with female cuckoo bubbling calls. a All birds shown. b Only cases when cuckoos approached the speaker are shown $\left(n_{\text {females }}=10, n_{\text {males }}=15\right.$, out of 16

trials). $* P<0.05, * * P<0.01 ; * * * P<0.001$. The box plot shows the median (central horizontal line), 75th and 25th percentiles (top and bottom of the box), and the maximum and minimum values (top and bottom whisker), respectively 
Table 1 Frequency of call types (yes/no in a trial) uttered by male common cuckoos in the 2-min playback period of female cuckoos' bubbling calls and in the 2-min post-playback period. The same frequencies are also shown for the collared dove control playbacks

\begin{tabular}{lcc}
\hline Call types & $\begin{array}{l}\text { Frequencies to } \\
\text { playback }\end{array}$ & $\begin{array}{l}\text { Frequencies to control } \\
\text { playback }\end{array}$ \\
\hline Cu-coo & $15^{\mathrm{a}}$ & $10^{\mathrm{b}}$ \\
Quick cu-cu-coo & 6 & $1^{\mathrm{c}}$ \\
Gowk & 11 & 1 \\
Guo & 2 & 0 \\
$N_{\text {trials with male cuckoo's present }}$ & 15 & 12 \\
$N_{\text {trials }}$ & 16 & 16 \\
\hline
\end{tabular}

a In one additional trial the "cu-coo" call was also heard from 60 to $70 \mathrm{~m}$ (outside of the 50-m action radius)

b In three more trials, male cuckoos uttered "cu-coo" calls outside the action radius $(>50 \mathrm{~m})$

c In one more case, male's quick "cu-cu-coo" was heard from about 60 $80 \mathrm{~m}$

The PCA of female playbacks revealed two main components (Fig. 5a; Table 2). The first component (PC1) is composed of the variables "number of females" and "number of calls" with high positive loadings; PC2 is related to "closest distance" (Table 3). PC1 shows that the presence of more females at a site increases female calling activity.

The PCA of males resulted in two main components (Fig. 5 b; Table 2). PC1 is explained by "closest distance", and, with opposite signs, "number of males" attracted. PC2 is partly explained by "number of call types" and "largest distance" with an opposite sign (Table 3). We consider that the difference revealed by the two PCAs is related to the function of female calls regarding conspecific females vs. males.

Our first generalized model revealed that movement distance was affected by treatment (experiment/control), starting distance, and the interaction of these terms (Table 4). The effect of playback treatment showed that cuckoos responded significantly stronger to bubbling call playbacks than to dove controls. The statistically significant effect of starting distance in the model showed that birds moved further to the speaker when starting distance was longer. The second model revealed that treatment also affected cuckoos' vocal responses significantly or responses uttered to the bubbling call playback than to the control (Table 4).

\section{Discussion}

Our results revealed that female cuckoos give their characteristic bubbling calls more often than previously thought (c.f. Wyllie 1981) in the context of playbacks of other females' bubbling calls, consistent with an intraspecific function that it may serve in territorial defense. Female cuckoos typically a

Females

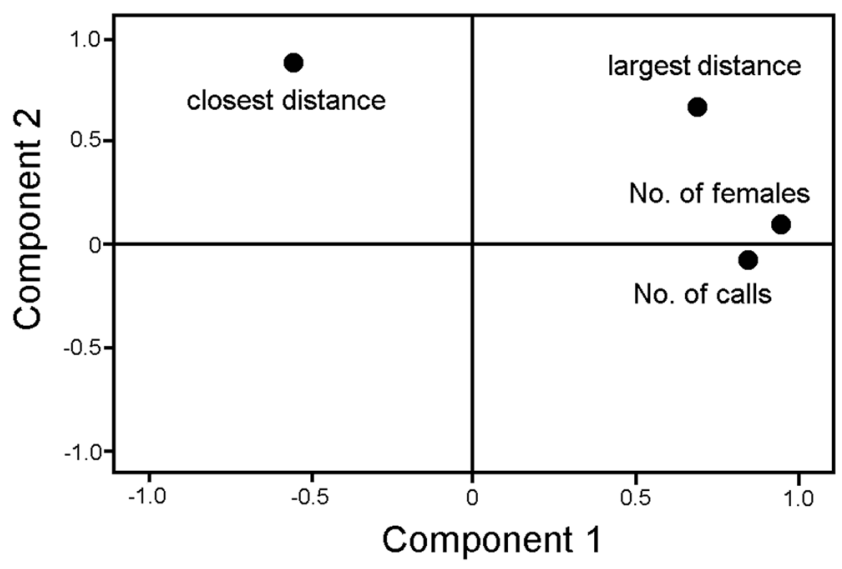

b Males

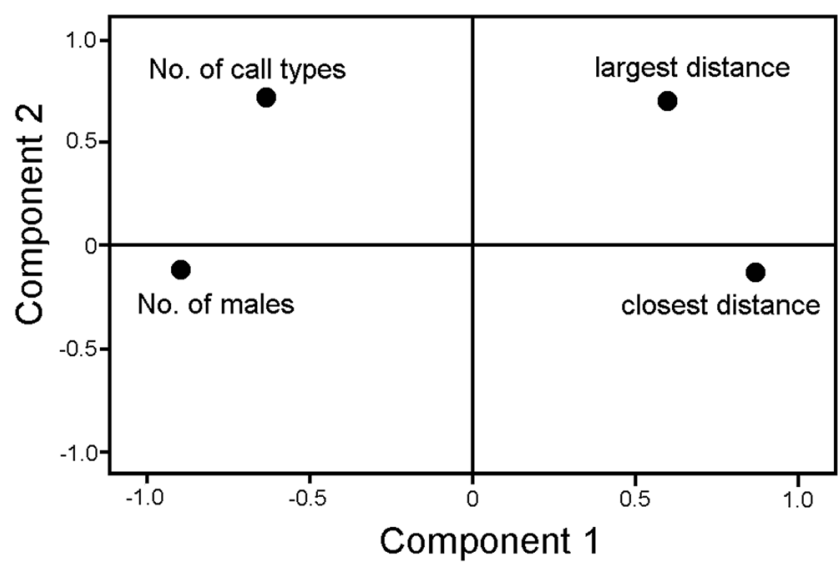

Fig. 5 Ordination diagram of two principal component analyses on female (a) and male (b) common cuckoos, based on response behavioral variables to playback of female cuckoo bubbling calls. The original response variables are displayed as component loadings in relation to the first two principal components

responded to playback within a few seconds, implying a high valence to this signal. During playbacks, we observed on several occasions that females uttered their bubbling calls up to 2-3 times in a minute, and sometimes under natural circumstances certain females called every $2-3 \mathrm{~min}$. It was more frequent than Wyllie (1981) observed it in a low-density cuckoo population breeding in a reed warbler (A. scirpaceus) host habitat in England (ca. 0.27 calls per hour). We consider the possibility that females produced more calls in our dense population of cuckoos because of the higher frequency of interactions with conspecific females.

However, our playback also attracted male cuckoos, implying a role of the bubbling call also in male-female social relationships. Specifically, males approached the speaker, and more males were attracted during the experiments than females. This may reflect a male sex-ratio bias in breeding populations of cuckoos, differences in the spatial configuration of 
Table 2 Eigenvalues and variance explained by PCAs on female and male cuckoo responses to playback of female cuckoo calls

\begin{tabular}{llllll}
\hline Principal component (PC) & \multicolumn{2}{l}{ Females } & & \multicolumn{2}{l}{ Males } \\
\cline { 2 - 3 } \cline { 5 - 6 } & Eigenvalue & Variance explained \% & & Eigenvalue & Variance explained \% \\
\hline 1 & 1.962 & 49.05 & 2.254 & 56.35 \\
2 & 0.942 & 23.56 & 0.972 & 24.30 \\
3 & 0.673 & 16.83 & 0.498 & 12.46 \\
4 & 0.423 & 10.57 & 0.276 & 6.89 \\
\hline
\end{tabular}

males and females, a higher salience of female calls to males than to females in this parasitic species, or a socially complex hierarchy among females themselves (sensu Davies 2000); all these alternatives deserve future studies. Our results are in accordance with Chance (1940), who thought that bubbling call is emitted when a female cuckoo seeks to call in the male. We observed female cuckoos giving their bubbling calls when they flew together with a male (called "tandem flight" by Mikulica et al. 2017) with, the male producing "gowk" calls. Our work on radio tracking cuckoos (Moskát et al. 2017a, 2019) was suggestive that females are spaced more evenly than males and show less mobility toward neighboring territories, but quantitative analyses of these patterns across the sexes are still lacking. Neither female nor male cuckoos approached the speaker when calls of dove control were played, similar to our previous results for male cuckoos, as they did not respond to collared dove playbacks at all (Moskát et al. 2017a, 2018).

Although male cuckoos have several more call types in addition to their well-known advertising call ("cu-coo"), female cuckoos appear to have only one, the bubbling call. Nonetheless, together with other interspecific signaling work (York and Davies 2017), our intraspecific results imply that a simple call type, female cuckoo bubbling call, can have multiple and diverse communication functions. Regarding the interspecific signaling function of the female bubbling call (York and Davies 2017), we did not address this role explicitly in our study. However, misdirected signaling of the parasite's identity, by mimicking a hawk call, may be important in female cuckoos parasitizing great reed warblers and other hosts in Hungary, as observers have repeatedly detected female cuckoo feathers at host nests in our study site and elsewhere (e.g., Varga 1994). These observations show an injury cost paid by female cuckoos of direct encounters with nestdefensive hosts, including death by drowning (Molnár 1944); such fatal costs were also observed in hosts of other brood parasitic taxa (Gloag et al. 2013).

Our results also revealed the use of not only common but also rare call types in male cuckoos in the context of intersexual communication, which has not been studied previously in detail. For instance, males uttered the quick "cu-cu-coo" in the vicinity of our female playbacks. In turn, "gowk" is more often used in male-female communication, and we also observed it in response to our playbacks. The role of the "guo" call is not known, although it may probably be used for contact with his mate (Lei et al. 2005). Finally, a recent study has revealed that males' most common and general advertising call ("cu-coo") is used for advertising territories and territory defense, not for sexual attraction (Moskát et al. 2017a).

Taken together, increasing work on female cuckoo's bubbling calls has revealed that a simple call type could serve as a multi-meaning (pluripotential, sensu Hebets et al. 2016) signal for different receivers, toward conspecific females, conspecific males, and heterospecific hosts. As reproduction in parasitic cuckoos and other avian brood parasites strongly depends on the availability of host nests at the suitable stage (e.g., Fiorini et al. 2009; Scardamaglia and Reboreda 2014; Soler et al. 2015; Geltsch et al. 2016), guarding to maintain exclusive access to these host nests seems to be critically important for cuckoos (Davies 2015). In our study area, more than one female cuckoos could lay into the same host nests (e.g., Moskát et al. 2009; Zölei et al. 2015), which means that female cuckoos' attempts to monopolize territories or egg-laying ranges are far from perfect.
Table 3 Component correlations between response variables and components (PC) obtained by PCAs on female and male cuckoos in response to playback of female cuckoo calls

\begin{tabular}{|c|c|c|c|c|}
\hline \multirow[t]{2}{*}{ Response variables } & \multicolumn{2}{|l|}{ Females } & \multicolumn{2}{|l|}{ Males } \\
\hline & $\mathrm{PC} 1$ & $\mathrm{PC} 2$ & $\mathrm{PC} 1$ & $\mathrm{PC} 2$ \\
\hline Number of birds & 0.855 & 0.0 .65 & -0.859 & -0.110 \\
\hline Closest distance & -0.501 & 0.769 & 0.897 & -0.095 \\
\hline Largest distance & 0.629 & 0.586 & 0.586 & 0.693 \\
\hline No. of calls (for females) / No. of call types (for males) & 0.764 & -0.050 & -0.606 & 0.686 \\
\hline
\end{tabular}


Table 4 The effects of sex and treatment factors, and starting distance as a covariate on the dependent variables of movement distance and number of calls

\begin{tabular}{llccc}
\hline Dependent variable & Independent variables & Wald chi-square & df & $P$ \\
\hline Movement distance & Intercept & 0.586 & 1 & 0.444 \\
& Sex & 0.080 & 1 & 0.778 \\
& Treatment & 3.967 & 1 & $0.046^{*}$ \\
& Starting distance & 10.328 & 1 & $0.001^{* *}$ \\
& Sex $\times$ starting distance & 0.424 & 1 & 0.515 \\
No. of calls & Treatment $\times$ starting distance & 17.734 & 1 & $<0.001^{* *}$ \\
& Intercept & 73.840 & 1 & $<0.001^{* *}$ \\
& Sex & 0.079 & 1 & $<0.0779$ \\
& Treatment & 57.867 & 1 & $<0.001^{* *}$ \\
& Sex $\times$ treatment & 0.010 & 1 & 0.921 \\
\hline
\end{tabular}

$* P<0.05$

$* * P<0.001$

Except for the hole-nesting redstarts (Phoenicurus phoenicurus) (e.g., Rutila et al. 2002; Grim et al. 2009), the young cuckoo chick evicts all eggs or nestlings from the nest (Honza et al. 2002; Moskát et al. $2017 b$ ), so consequently only one cuckoo chick can be fledged from a great reed warbler nest. This means the waste of other cuckoo eggs laid into multiple parasitized nests (Takasu and Moskát 2011). In non-evictor brood parasites, like the great spotted cuckoo (Clamator glandarius) in which hosts and brood parasitic nestlings may grow up together (Soler and Soler 2000), territoriality has less importance and may be lacking even when multiple parasitism occurs (Martínez et al. 1998). For this reason, we suggest that future studies should examine whether and how female common cuckoos guard and protect their critical resources for their reproduction (host nests) and to examine how their acoustic communications serve the prevention of interfemale aggression and may exhibit dominance hierarchies. For example, Gärtner (1981) suggested that there are different classes in female cuckoo social interactions; he observed that dominant females showed territoriality, whereas subordinate females had overlapping laying areas in the territory of one (or more) dominant female(s). He also revealed that some of the females were non-resident birds, laying into suitable nests found along their movement routes. Davies (2000) also suggested that dominance may exist among female cuckoos, with subordinate females taking over the laying area when dominant females die. Our results revealed that female cuckoos were interested in bubbling calls of other females, revealing consistent with the territorial function of female cuckoo calls. This finding supports the expectation of Davies (2015), as the bubbling call could be a "keep out" signal for other females. However, we also found much variation in the responses of female cuckoos to the playbacks, implying that vocal communication could serve not only in detecting the current location of females in general, but also in mediating the interactions of dominant vs. subdominant female cuckoos along territorial boundaries.

Acknowledgments Open access funding provided by Hungarian Natural History Museum (MTM). The authors thank Zoltán Elek for assistance with the fieldwork. We are grateful to the editor and the anonymous referees for their constructive comments.

Funding The study was supported by the National Research, Development and Innovation Office, Hungary to CM (grant no. NN118194). Additional funding was received from the USA National Science Foundation (IOS \#1456524) to MEH.

\section{Compliance with ethical standards}

Conflict of interest The authors declare that they have no conflict of interest.

Ethical approval All applicable international, national, and/or institutional guidelines for the care and use of animals were followed. Local ethical regulations and agreements were followed for fieldwork. All work complied with the Hungarian laws, and the Middle-Danube-Valley Inspectorate for Environmental Protection, Nature Conservation and Water Management, Budapest, provided permission for research (permit no. $\mathrm{PE} / \mathrm{KTF} / 17190-3 / 2015)$.

Open Access This article is distributed under the terms of the Creative Commons Attribution 4.0 International License (http:// creativecommons.org/licenses/by/4.0/), which permits unrestricted use, distribution, and reproduction in any medium, provided you give appropriate credit to the original author(s) and the source, provide a link to the Creative Commons license, and indicate if changes were made.

\section{References}

Appleby BM, Yamaguchi M, Johnson PJ, MacDonald DW (1999) Sexspecific territorial responses in Tawny Owls Strix aluco. Ibis 141: 91-99

Bán M, Moskát C, Fülöp A, Hauber ME (2018) Return migration of common cuckoos (Cuculus canorus) between breeding grounds in 
Hungary and wintering grounds in Africa as documented by nonPTT GPS technology. J Ornithol 159:337-344

Beecher MD, Brenowitz EA (2005) Functional aspects of song learning in songbirds. Trends Ecol Evol 20:143-149

Bradbury JW, Vehrencamp SL (1998) Principles of animal communication. Sinauer, Sunderland, MA

Budka M, Osiejuk TS (2013) Neighbour-stranger call discrimination in a nocturnal rail species, the corncrake Crex crex. J Ornithol 154:685694

Budka M, Osiejuk TS (2017) Microgeographic call variation in a nonlearning species, the corncrake (Crex crex). J Ornithol 158:651-658

Catchpole CK, Slater PJB (2008) Bird song: biological themes and variations, 2nd edn. Cambridge University Press, Cambridge

Chance EP (1940) The truth about the cuckoo. Country Life Ltd., London, UK

Cramp S (1985) Handbook of the birds in Europe and Middle East and North Africa. The birds of the Western Palearctic, vol 4. Oxford University Press, Oxford

Davies NB (2000) Cuckoos, cowbirds and other cheats. Poyser, London Davies NB (2015) Cuckoo. Cheating by nature. Bloomsbury Publ, London

Deng Z, Lloyd H, Xia C, Møller AP, Liang W, Zhang Y (2019) Components of variation in female common cuckoo calls. Behav Process 158:106-112

Dröscher L (1988) A study on radio-tracking of the European Cuckoo (Cuculus canorus canorus). In: van den Elzen R, Schuchmann K-L, Schmidt-Koenig K (eds) Proceedings of the International 100th Deutsche Ornithologische-Geselschaft Meeting. Deutsche Ornithologen-Gesselschaft, Bonn, Germany, pp 187-193

Erritzøe J, Mann CF, Brammer FP, Fuller RA (2012) Cuckoos of the world. Bloomsbury, London

Fedy BC, Stutchbury BJM (2005) Territory defence in tropical birds: are females as aggressive as males? Behav Ecol Sociobiol 58:414-422

Fiorini VD, Tuero DT, Reboreda JC (2009) Shiny cowbirds synchronize parasitism with host laying and puncture host eggs according to host characteristics. Anim Behav 77:561-568

Gärtner K (1981) Das Wegnehmen von Wirstvogeleiern durch den Kuckuck Cuculus canorus. Ornithol Mitt 33:115-131

Geltsch N, Bán M, Hauber ME, Moskát C (2016) When should common cuckoos Cuculus canorus lay their eggs in host nests? Bird Study 63:46-51

Gloag R, Fiorini VD, Reboreda JC, Kacelnik A (2013) The wages of violence: mobbing by mockingbirds as a frontline defence against brood-parasitic cowbirds. Anim Behav 86:1023-1029

Grim T, Rutila J, Cassey P, Hauber ME (2009) Experimentally constrained virulence is costly for common cuckoo chicks. Ethology 115:14-22

Hauber ME, Dearborn DC (2003) Parentage without parental care: what to look for in genetic studies of obligate brood-parasitic mating systems. Auk 120:1-13

Hauber ME, Russo SA, Sherman PW (2001) A password for species recognition in a brood-parasitic bird. Proc R Soc Lond B 268: 1041-1048

Hebets EA, Barron AB, Balakrishnan CN, Hauber ME, Mason PH, Hoke KL (2016) A systems approach to animal communication. Proc R Soc B 283:20152889

Honza M, Sicha V, Prochazka P, Lezalová R (2006) Host nest defense against a color-dimorphic brood parasite: great reed warblers (Acrocephalus arundinaceus) versus common cuckoos (Cuculus canorus). J Ornithol 147:629-637

Honza M, Taborsky B, Taborsky M, Teuschl Y, Vogl W, Moksnes A, Røskaft E (2002) Behaviour of female common cuckoos, Cuculus canorus, in the vicinity of host nests before and during egg laying: a radiotelemetry study. Anim Behav 64:861-868
Jung WJ, Lee JW, Yoo JC (2014) “Cu-coo": can you recognize my stepparents? A study of host-specific male call divergence in the common cuckoo. PLoS One 9:e90468

Kim H, Lee J-W, Yoo J-C (2017) Characteristics of female calls of four Cuculus species breeding in Korea. Korean J Ornithol 24:41-47 (in Korean, abstract in English)

Kleven O, Moksnes A, Røskaft E, Honza M (1999) Host species affects the growth rate of cuckoo (Cuculus canorus) chicks. Behav Ecol Sociobiol 47:41-46

Kroodsma DE (1989) Suggested experimental designs for song playbacks. Anim Behav 37:600-609

Ladich F, Winkler H (2017) Acoustic communication in terrestrial and aquatic vertebrates. J Exp Biol 220:2306-2317

Lei F-M, Zhao H-F, Wang A-Z, Yin Z-H, Payne RB (2005) Vocalizations of the common cuckoo Cuculus canorus in China. Acta Zool Sin 51: $31-37$

Leisler B, Schulze-Hagen K (2011) Reed warblers: diversity in a uniform bird family. KNNV Publishing, Zeist, The Netherlands

Li Y, Xia C, Lloyd H, Li D, Zhang Y (2017) Identification of vocal individuality in male cuckoos using different analytical techniques. Avian Res 8:21

MacDougall-Shackleton SA (1997) In: Nolan V Jr, Ketterson ED, Thompson CF (eds) Current ornithology, vol 14. Plenum Press, New York, pp 81-124

Mann C (2014) Common and oriental cuckoos: photo guide. Birdwatch June 2014: 45-52

Martínez JG, Soler JJ, Soler M, Burke T (1998) Spatial patterns of egg laying and multiple parasitism in a brood parasite: a non-territorial system in the great spotted cuckoo (Clamator glandarius). Oecologia 117:286-294

McGregor PK, Dabelsteen T (1996) Communication networks. In: Kroodsma DE, Miller EH (eds) Ecology and evolution of acoustic communication in birds. Cornell University Press, Ithaca, NY, pp $409-425$

Mikulica O, Grim T, Schulze-Hagen K, Stokke BG (2017) The cuckoo: the uninvited guest. Wild Nature Press, Plymouth

Molnár B (1944) The cuckoo in the Hungarian Plane. Aquila 51:100-112

Moskát C, Bán M, Fülöp A, Bereczki J, Hauber ME (2019) Bimodal habitat use in brood parasitic Common Cuckoos (Cuculus canorus) revealed by GPS telemetry. Auk (published online doi:10.109/auk/ uky019)

Moskát C, Barta Z, Hauber ME, Honza M (2006) High synchrony of egg laying in common cuckoos (Cuculus canorus) and their great reed warbler (Acrocephalus arundinaceus) hosts. Ethol Ecol Evol 18: $159-167$

Moskát C, Elek Z, Bán M, Geltsch N, Hauber ME (2017a) Can common cuckoos discriminate between neighbours and strangers by their calls? Anim Behav 126:253-260

Moskát C, Hauber ME, Avilés JM, Bán M, Hargitai R, Honza M (2009) Increased host tolerance of multiple cuckoo eggs leads to higher fledging success of the brood parasite. Anim Behav 77:1281-1290

Moskát C, Hauber ME, Bán M, Fülöp A, Geltsch N, Marton A, Elek Z (2018) Are both notes of the common cuckoo's call necessary for familiarity recognition? Behav Process 157:685-690

Moskát C, Hauber ME, Louder MIM (2017b) The evolution of nest sharing and nest mate killing strategies in brood parasites. In: Soler M (ed) Avian brood parasitism: behaviour, ecology, evolution and coevolution. Springer Int. Publ, Cham, Switzerland, pp 475 492

Naguib M (2005) Singing interactions in songbirds: implications for social relations and territorial settlement. In: McGregor PK (ed) Animal communication networks. Cambridge University Press, Cambridge, pp 300-319

Nakamura H, Miyazawa Y (1997) Movements, space use and social organization of radio-tracked common cuckoos during the breeding season in Japan. Jpn J Ornithol 46:23-54 
Payne RB (1986) Bird songs and avian systematics. In: Johnstone RF (ed) Current ornithology, vol 3. Plenum Press, New York, pp 87-125

Payne RB (2005) The cuckoos. Oxford University Press, Oxford

Rek P (2014) Acoustic location of conspecifics in a nocturnal bird: the corncrake Crex crex. Acta Ethol 17:31-35

Rutila J, Latja R, Koskela K (2002) The common cuckoo Cuculus canorus and its cavity nesting host, the redstart Phoenicurus phoenicurus: a peculiar cuckoo-host system? J Avian Biol 33:414 419

Scardamaglia RC, Reboreda JC (2014) Ranging behavior of female and male shiny cowbirds and screaming cowbirds while searching for host nests. Auk 131:610-618

Soler JJ, Soler M (2000) Brood-parasite interactions between great spotted cuckoos and magpies: a model system for studying coevolutionary relationships. Oecologia 125:309-320

Soler M, Pérez-Contreras T, Soler JJ (2015) Synchronization of laying by great spotted cuckoos and recognition ability of magpies. J Avian Biol 46:608-615

Takasu F, Moskát C (2011) Modeling the consequence of increased host tolerance toward avian brood parasitism. Popul Ecol 53:187-193

Tryjanowski P, Morelli F, Osiejuk TS, Møller AP (2018) Functional significance of cuckoo Cuculus canorus calls: responses of conspecifics, hosts and non-hosts. PeerJ 6:e5302

Varga F (1994) Cuckoo observations around the source of the river Zagyva. Published by the author, Salgótarján, Hungary

Vogl W, Taborsky B, Taborsky M, Teuschl Y, Honza M (2004) Habitat and space use of European Cuckoo females during the egg laying period. Behaviour 141:881-898
Wei C, Jia C, Dong L, Wang D, Xia C, Zhang Y, Liang W (2015) Geographic variation in the calls of the common cuckoo (Cuculus canorus): isolation by distance and divergence among subspecies. J Ornithol 156:533-542

Witherby, Jourdain FCR, Ticehurst NF, Tucker BW (1940) Handbook of British birds, vol II. H.F. \& G. Witherby Ltd., London

Wojas LE, Podkowa PW, Osiejuk TS (2018) A nocturnal rail with a simple territorial call eavesdrops on interactions between rivals. PLoS One 13:e197368

Wyllie I (1981) The cuckoo. Batsford, London

York JE, Davies NB (2017) Female cuckoo calls misdirect host defences towards the wrong enemy. Nat Ecol Evol 1:1520-1525

Zölei A, Bán M, Moskát C (2015) No change in common cuckoo Cuculus canorus parasitism and great reed warblers' Acrocephalus arundinaceus egg rejection after seven decades. J Avian Biol 46: 570-576

Zsebök S, Moskát C, Bán M (2017) Individually distinctive vocalization in common cuckoos (Cuculus canorus). J Ornithol 158:213-222

Publisher's note Springer Nature remains neutral with regard to jurisdictional claims in published maps and institutional affiliations. 